Saudi Journal of Oral and Dental Research

Abbreviated Key Title: Saudi J Oral Dent Res ISSN 2518-1300 (Print) |ISSN 2518-1297 (Online) Scholars Middle East Publishers, Dubai, United Arab Emirates Journal homepage: http://scholarsmepub.com/sjodr/

Review Article

\title{
Nanotechnology in Orthodontics - A Review
}

\author{
Dr. Arwa Saifee ${ }^{1 *}$, Dr. Sandhya Jain ${ }^{2}$
}

${ }^{1}$ PG Student Department of Orthodontics and Dentofacial Orthopedics

${ }^{2}$ Prof and Head Department of Orthodontics and Dentofacial Orthopedics

\author{
DOI: $10.36348 /$ sjodr.2019.v04i11.007 \\ | Received: 21.11.2019 | Accepted: 28.11.2019 | Published: 30.11.2019 \\ *Corresponding author: Arwa Saifee
}

\section{Abstract}

Nanotechnology has proven to be a boon to entire field of dentistry. This review article provides update about nanotechnology in orthodontics and various treatment modalities available with newer technology especially in field of dentistry.

Keywords: Shape memory polymers, Nano materials, Nano composites, BIO MEMS AND NEMS.

Copyright @ 2019: This is an open-access article distributed under the terms of the Creative Commons Attribution license which permits unrestricted use, distribution, and reproduction in any medium for non-commercial use (NonCommercial, or CC-BY-NC) provided the original author and source are credited.

\section{INTRODUCTION}

Nano-technology is a revolution in almost all disciplines of life today. Nanotechnology approaches the manipulation of matter at atomic and molecular level. This technology, which deals with matter in nanodimensions, has widened our views of poorly understood health issues and provided novel means of diagnosis and treatment. Dentistry, particularly orthodontics not being an exception, also faces major revolutions to constantly provide better and more comfortable dental care to patients.
As Dentistry, on whole comprises of many interdisciplinary branches, and all of which finds nanotechnology in use, which is again a interdisciplinary field comprising of nano robotics, nano electronics, nano materials, and nanobiotechnology. Each of these has different application in different areas of dentistry like advanced diagnosis in oral medicine and diagnosis, local drug Delivery and anesthesia in oral surgery and periodontal drug delivery, biomechanics in orthodontics.

\section{Nanotechnology in orthodontics}

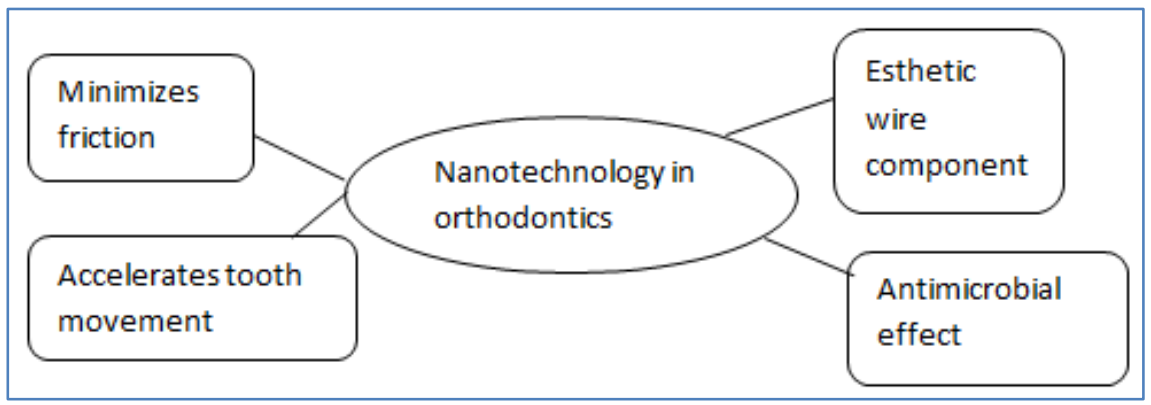

Nanocoatings in archwires- The time taken in orthodontic tooth movement is the biggest hurdle which needs a quick correction with better retention and stability. Minimizing the frictional forces between the orthodontic wire and brackets can increase the desired tooth movement and subsequently result in less treatment time. In recent years dry lubricant uses nanoparticles as a component. Dry lubricants are solid phase materials. These are capable to reduce friction between two surfaces sliding against each other without the need for a liquid media, thus reducing the friction between two materials. Inorganic fullerene-like nanoparticles of tungsten sulflide (IF-WS2), which are potent dry lubricants, have been used as self-lubricating coatings for orthodontic stainless steel wires [1].

A study showed stainless steel wire coated with nickel- phosphorous electrolyte film which was impregnated with inorganic fullerene-like nanoparticles of tungsten disulfide (IF-WS2). Friction tests of 
archwire functioning of the coated and uncoated wires were carried out by an Instron machine and SEM/EDS analysis of the coated wires showed clear impregnation of the IF-WS2 nanoparticles in the Ni-P matrix. The friction forces measured on the coated wire were reduced by up to $54 \%$ [1].

Nanoparticle in Orthodontic adhesive Polymer nanocomposites is a new smart material that contains nano fillers. These are 0.005- 0.01 microns in size. Due to the reduced dimension of the particles and a wide size distribution the filler load can be increased that increases mechanical properties such as tensile and compressive strength and resistance to fracture and also reduces polymerization shrinkage [2].

Geraldeli and Perdigao reported that nanocomposites had a good marginal seal to enamel and dentine compared with total-etch adhesives. The advantages of nanocomposite materials include excellent optical properties, easy handling characteristics and superior polishiability.

Also, nanofillers can decrease surface roughness of orthodontic adhesives, which is one of the most significant factors for bacterial adhesion. The results suggest that Nano-composites and nanoionomers may be suitable for bonding.But they are inferior to a conventional orthodontic composite [3].

Bishara and Ajlouni compared the shear bond strength of a nano- hybrid restorative material, Grandio (Voco, Germany), and traditional adhesive material (Transbond XT; 3M Unitek) when bonding orthodontic brackets. They concluded that nano- filled composite materials can potentially be used to bond orthodontic brackets to teeth if its consistency can be made more flowable to readily adhere to the bracket base [4].

Nanoparticle delivery from elastomeric ligature Elastomeric ligatures can serve as a carrier base for delivery of nanoparticles which can render anticariogenic, antiinflammatory and antibiotic properties .Literature have shown The release of anticariogenic fluoride from elastomeric ligatures. The studies conclude that the, fluoride particles could be dispensed from elastomeric ligature which is characterized by an initial burst of fluoride during the first few days followed by a logarithmic decrease. Gabriel et al. demonstrated antibacterial properties of silver nano particles against streptococcus mutans in a in vitro study conducted in $2009[5,6]$.

Shape memory polymers in orthodontics: Over the past decade there has been an increased interest in manufacturing esthetic orthodontic wires to complement tooth coloured brackets where the shape memory polymers come to their rescue [7, 8]. Mechanism Of Action - Shape memory polymers (SMPs) are materials that have the ability to memorize a macroscopic shape. These can be then manipulated and conferred to a temporary shape under specific conditions of temperature and stress. These materials can later relax to the original, stress-free condition under thermal, electrical, or environmental condition. Once placed in the mouth, these polymers can be activated by the body temperature or photoactive nanoparticles activated by light and thus bring about tooth movement. The SMP wires can provide improvements over conventional orthodontic materials as they will provide lighter, more constant forces which in turn may cause less pain for the patients.

Polymer and SMP polymer with blends [9] are also available like the one with blending with various polymers like poly vinyl flouirde or elastomeric ionomer or carbon nano tubes reinforced which renders the SMPs with UV protection. Control of oral Biofilms during orthodontic treatment- Nano particles present a greater surface area when compared with non-nanoscale particles, interacting more closely with microbial membranes and therefore provide considerably larger surface area for antimicrobial activity. Metal NPs in the size range of 1-10 $\mathrm{nm}$ have particularly shown the greatest bacteriocidal activity against bacteria. Silver is known for antimicrobial properties since ages. [10]. Resin composites containing silver ion-implanted fillers that release silver ions have been found to have antibacterial effects on oral streptococci. S J Ahn et al. reported an experimental composite adhesive (ECAs) containing silica nanofillers and silver nanoparticles with two conventional composite adhesives and resin modified glass ionomer [RMGI]) that ECAs had rougher surfaces than conventional adhesives due to the addition of silver nanoparticles [11]. Bacterial adhesion to ECAs was less than conventional adhesives, which was not influenced by saliva coating. This study suggested that ECAs can help prevent enamel demineralization around brackets without compromising physical properties [12].

\section{Bio MEMS/NEMS for orthodontic tooth movement-} $[13,14]$

They are made up of micromachined elements usually made of sillicon, including gears, motors with linear and rotary motion for applications to biological systems. Nanoelectromechanical systems (NEMS) are devices which combines electrical and mechanical functionality on the nanoscale level. According to the evidence orthodontic tooth movement can be enhanced by supplementing the mechanical forces with electricity. Animal studies have shown increased tooth movement on giving the electric stimulation which enhances cellular enzymatic phosphorylation activities, and leads to accelerated tooth movement [15].

Temporary anchorage devices- Temporary anchorage devices have gained a lot of popularity in clinicians. Recently, TADs are manufactured with smooth titanium surfaces because complete 
osseointegration is a disadvantage that complicates their removal. But lack of osseointegration is also one of the factors for the failure of TADs. Therefore the balance is required that could stimulate initial ossointegration and also facilitate its removal once the TAD is needed. Biocompatible coatings like Titanium nanotubes can be applied to evaluate if this can enhance initial osseointegration and can serve as an interfacial layer between the newly formed bone and the TAD $[15,16]$.

Nano LIPUS devices Ultrasound is a form of mechanical energy that is transmitted through and into biological tissues as an acoustic pressure wave, is used widely in medicine as a therapeutic, operative, and diagnostic tool. Low-intensity pulsed US (LIPUS) has shown to be effective in liberating preformed fibroblast growth factors from a macrophage-like cell line (U937), and it enhances angiogenesis during wound healing. Also, LIPUS has been reported to enhance bone growth into titanium porous-coated implants and also bone healing after fracture and after mandibular distraction osteogenesis. The specific mechanisms by which US stimulation works on bone cell activities are still unknown [17].

El-Bialy et al. [18] applied LIPUS on the temporomandibular joint (TMJ) region of growing rabbits and baboon monkeys for few minutes daily. Their results have shown a significant increase in mandibular cartilaginous growth. In another study by Oyonartea et al. experimental rats were stimulated with LIPUS in the TMJ region unilaterally, for 10 or 20 minutes for 20 days. The results showed that LIPUS application can affect mandibular growth pattern in rats which acts at cartilage and bone level [19]. Another application of this technique is to reduce root resorption during orthodontic treatment. Based on their observation that LIPUS can promote dental tissue formation in rabbits, el-Bialy et al. concluded that it may be used to treat root resorption.

Smart brackets with nanomechanical sensorsknowledge of the three dimensional (3D) force-moment systems applied for orthodontic tooth movement is of utmost importance to predict the course of tooth movement as well as the reduction of traumatic side effects. This concept of a smart bracket with integrated sensor system for 3D force and moment measurement has shown to work well. Nanomechanical sensors can be fabricated and be incorporated into the base of orthodontic brackets to provide a clear assessment of the applied orthodontic forces, which allows precise application of force by orthodontist [20].

These smart brackets rely on an innovative clip system to hold the wires in place. They're available in both metal and a translucent ceramic material designed to blend in with the teeth for a less noticeable presentation [21].

\section{CONCLUSION}

Thus nanotechnology has found an irreplaceable position and made treatment more precise and handy for the benefit of patients. This evolved to a level that nano-dimensions are now defining the entire world.

\section{REFERENCE}

1. Redlich, M., Katz, A., Rapoport, L., Wagner, H. D., Feldman, Y., \& Tenne, R. (2008). Improved orthodontic stainless steel wires coated with inorganic fullerene-like nanoparticles of WS2 impregnated in electroless nickel-phosphorous film. dental materials, 24(12), 1640-1646.

2. Govindankutty, D. (2015). Applications of nanotechnology in orthodontics and its future implications: A review. Int. J. Appl. Dent. Sci, 1(4), 166-171.

3. Geraldi, S., \& Perdigao, J. (2003). Microleakage of a new restorative system in posterior teeth. $J$ Dent Res, 81, 1276.

4. Bishara, S. E., Ajlouni, R., Soliman, M. M., Oonsombats, C., Laffoon, J. F., \& Warren, J. (2007). Evaluation of a new nano-filled restorative material for bonding orthodontic brackets. World journal of orthodontics, 8(1).

5. Wiltshire, W. A. (1996). Determination of fluoride from fluoride-releasing elastomeric ligature ties. American journal of orthodontics and dentofacial orthopedics, 110(4), 383-387.

6. Miura, K. K., Ito, I. Y., Enoki, C., Elias, A. M., \& Matsumoto, M. A. N. (2007). Anticariogenic effect of fluoride-releasing elastomers in orthodontic patients. Brazilian oral research, 21(3), 228-233.

7. Meng, Q., \& Hu, J. (2009). A review of shape memory polymer composites and blends. Composites Part A: Applied Science and Manufacturing, 40(11), 1661-1672.

8. Gunes, I. S., \& Jana, S. C. (2008). Shape memory polymers and their nanocomposites: a review of science and technology of new multifunctional materials. Journal of Nanoscience and Nanotechnology, 8(4), 1616-1637.

9. Stuart, M. A. C., Huck, W. T., Genzer, J., Müller, M., Ober, C., Stamm, M., \& Winnik, F. (2010). Emerging applications of stimuli-responsive polymer materials. Nature materials, 9(2), 101.

10. Allaker, R. P. (2010). The use of nanoparticles to control oral biofilm formation. Journal of dental research, 89(11), 1175-1186.

11. Hill, W. R., \& Pillsbury, D. M. (1939). Argyria: the pharmacology of silver. Williams \& Wilkins Company.

12. Hannig, M., Kriener, L., Hoth-Hannig, W., Becker-Willinger, C., \& Schmidt, H. (2007). Influence of nanocomposite surface coating on biofilm formation in situ. Journal of Nanoscience and Nanotechnology, 7(12), 4642-4648. 
13. Gourley, P. L. (2005). Brief overview of BioMicroNano technologies. Biotechnology progress, 21(1), 2-10.

14. Nuxoll, E. E., \& Siegel, R. A. (2009). BioMEMS devices for drug delivery. IEEE Engineering in Medicine and Biology Magazine, 28(1), 31-39.

15. Net

16. Miyawaki, S., Koyama, I., Inoue, M., Mishima, K., Sugahara, T., \& Takano-Yamamoto, T. (2003). Factors associated with the stability of titanium screws placed in the posterior region for orthodontic anchorage. American Journal of Orthodontics and Dentofacial Orthopedics, 124(4), 373-378.

17. Kuroda, S., Sugawara, Y., Deguchi, T., Kyung, H. M., \& Takano-Yamamoto, T. (2007). Clinical use of miniscrew implants as orthodontic anchorage: success rates and postoperative discomfort. American Journal of Orthodontics and Dentofacial Orthopedics, 131(1), 9-15.
18. Young, S. R., \& Dyson, M. (1990). The effect of therapeutic ultrasound on angiogenesis. Ultrasound in medicine \& biology, 16(3), 261-269.

19. El-Bialy, T., Hassan, A., Albaghdadi, T., Fouad, H. A., \& Maimani, A. R. (2006). Growth modification of the mandible with ultrasound in baboons: a preliminary report. American Journal of Orthodontics and Dentofacial Orthopedics, 130(4), 435-e7.

20. Oyonarte, R., Zárate, M., \& Rodriguez, F. (2009). Low-intensity pulsed ultrasound stimulation of condylar growth in rats. The Angle Orthodontist, 79(5), 964-970.

21. Lapatki, B. G., \& Paul, O. (2007). Smart brackets for 3D-force-moment measurements in orthodontic research and therapy-developmental status and prospects. Journal of Orofacial Orthopedics/Fortschritte der Kieferorthopädie, 68(5), 377-396. 